\title{
CHALLENGES FOR THE LABORATORY BEFORE AND DURING AN INFLUENZA PANDEMIC
}

\author{
Dominic E Dwyer, Ken A McPhie \\ and V Mala Ratnamohan \\ Centre for Infectious Diseases and Microbiology \\ Laboratory Services \\ Institute of Clinical Pathology and Medical Research \\ Catherine NM Pitman \\ SDS Pathology
}

\section{ABSTRACT}

Laboratory tests that reliably confirm infection with a novel influenza strain are a major component of pandemic planning. Combined nose and throat swabs are the most practical respiratory tract sample to safely obtain from patients. As nucleic acid tests are sensitive, specific and rapid, they will be the diagnostic test of choice during a pandemic. Virus isolation (in laboratories with Physical Containment level 3 facilities) is required for characterisation of the pandemic strain and vaccine development. Antiviral resistance testing may be required if antiviral drugs are used extensively to help control a pandemic. Diagnostic strategies will vary throughout the various pandemic phases.

Laboratories, like all parts of the health sector, are currently formulating plans to provide appropriate services during an influenza pandemic. These services revolve around the provision of timely laboratory results to guide patient management and public health responses. They include the specific detection of the pandemic influenza virus in clinical samples, be it the currently circulating (but not yet detected in Australia) influenza A/H5N1 strain or a future novel strain. They also include differentiation of the pandemic strain from the other human influenza strains (influenza $\mathrm{A} / \mathrm{H} 3 \mathrm{~N} 2$ and $\mathrm{A} / \mathrm{H} 1 \mathrm{~N} 1$, and influenza $\mathrm{B}$ ) or other infectious causes of influenza-like illnesses. Laboratories will also need to support the clinical management of individuals already infected with influenza virus, for example by identifying and providing antibiotic sensitivity information for secondary bacterial infections. At the same time they will need to continue providing the usual pathology services for non-influenza related conditions.

The level of laboratory service will vary between different centres. Specialist virology laboratories will undertake a full range of influenza virus testing, including the rapid detection, culture and typing of isolates for potential use in vaccines, and the detection of antiviral drug resistance. Other laboratories may undertake a more limited range of services depending on their location (for example, in rural areas), their population (for example, in public or private hospitals) and access to specialised laboratories. The identification of the earliest cases of a novel influenza strain will require co-operation and communication between public health practitioners, treating clinicians and both public and private laboratories. These issues are discussed in the technical annexes of the Australian Health Management Plan for Pandemic Influenza and in the World Health Organization (WHO) and Centers for Disease Control (USA) pandemic plans. ${ }^{1-3}$

\section{LABORATORY DIAGNOSIS OF INFLUENZA}

\section{Collection of samples}

The key to successful laboratory diagnosis of influenza is the collection of the appropriate respiratory tract samples. This poses the challenge of ensuring that enough people are trained in safe and reliable specimen collection techniques prior to a pandemic. A swab from each nostril and a swab from the throat are recommended for adults (the specimens are combined in the laboratory, hence the name 'combined' nose and throat swab); nasopharyngeal aspirates may be collected in children less than three years of age. In severely ill hospitalised patients, lower respiratory tract samples such as bronchoalveolar lavage fluid are especially useful. Samples should be collected in the first three to four days following the onset of symptoms (as this is when the viral load is highest), and transported to the laboratory as quickly as possible. Early experience of human infection with influenza A/H5N1 infections suggests that the virus is more readily detectable in lower respiratory tract samples, although blood, faeces and cerebrospinal fluid may also contain virus. ${ }^{4,5}$

\begin{abstract}
Diagnostic methods
Table 1 lists the advantages, disadvantages and turnaround times of various laboratory methods for confirming influenza virus infection. The traditional or 'gold standard' method - isolation of influenza virus from the specimenrequires tissue culture facilities and particular expertise. With pandemic influenza, isolation will require a Physical Containment level 3 (PC3) laboratory ${ }^{1-3}$, where viruses can be then be typed as influenza A/H3N2, A/H1N1, A/H5N1 or $\mathrm{B}$ and later further evaluated to ensure that appropriate strains are used in vaccine preparation. Vaccine strain evaluation is undertaken through the WHO global influenza network. Australia is well-served by this network, with a WHO Collaborating Centre in Melbourne and WHO National Influenza Centres in Sydney (Institute of Clinical Pathology and Medical Research, Westmead), Melbourne (Victorian Infectious Diseases Reference Laboratory) and Perth (PathWest). ${ }^{6}$
\end{abstract}

Nucleic acid testing (NAT) is highly sensitive and specific for the detection of influenza and other respiratory virus genomes. ${ }^{7}$ Pandemic strain-specific NAT (for example, as developed for influenza A/H5N1) will be the diagnostic test of choice in a pandemic. ${ }^{1-3}$ It can be used on a range of clinical specimens and can be performed reasonably quickly, depending on the laboratory's testing platform. NAT can be directed against highly conserved regions of the influenza 


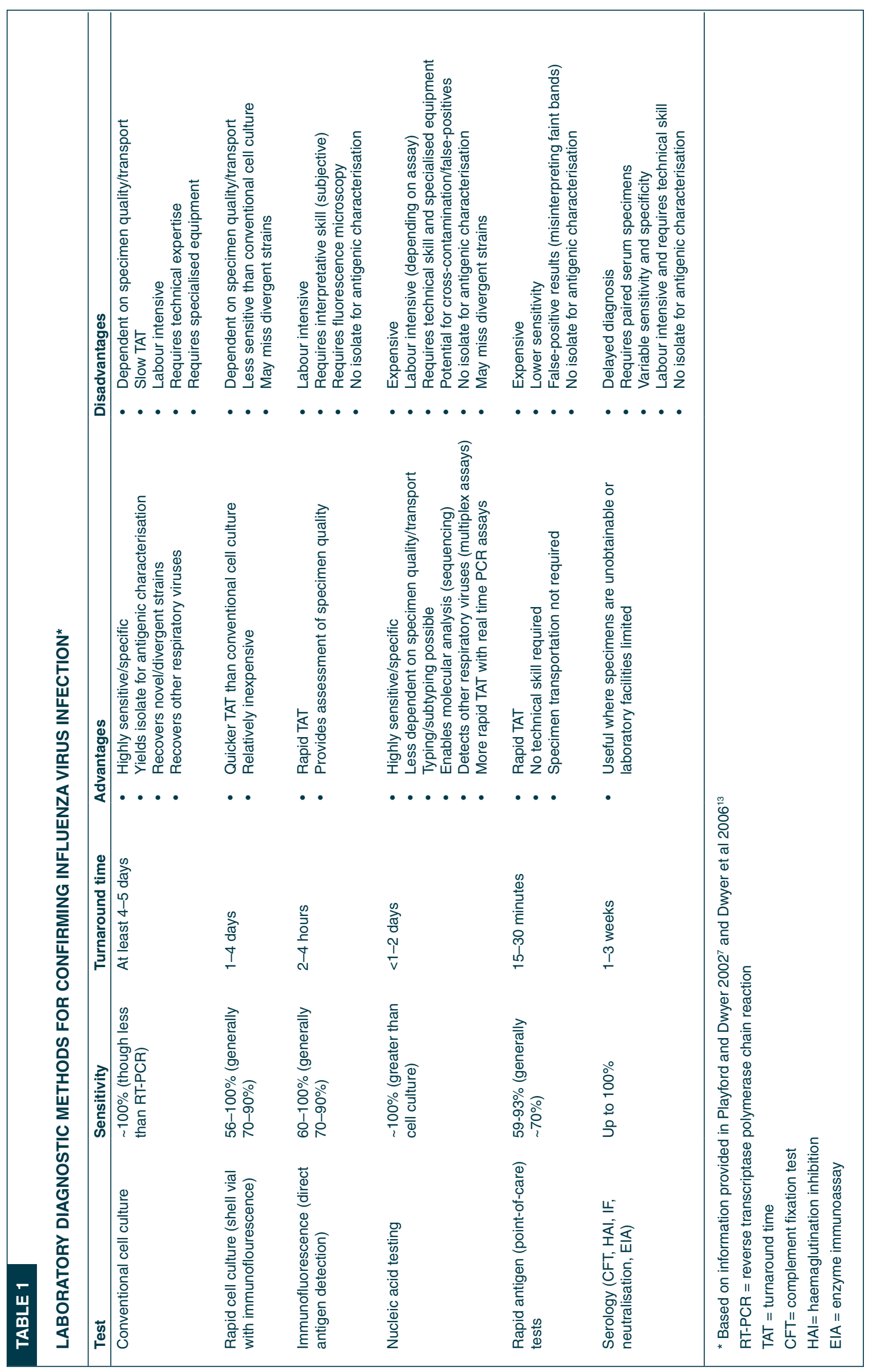


genome so that all human and avian influenza strains are detected, or it can be directed against specific regions of the influenza genome (for example, haemagglutinin or neuraminidase) to allow differentiation between influenza subtypes. Other molecular investigations such as sequencing influenza genes can be useful for detecting neuraminidase inhibitor drug resistance mutations ${ }^{8}$, or detecting relatedness between viral strains (for example in an outbreak setting). ${ }^{9,10}$ Although not routinely available, quantitative NAT can be used to measure the viral load in clinical samples, allowing a better understanding of disease pathogenesis, transmission and antiviral drug efficacy. ${ }^{11}$

Virus antigen and nucleic acid testing methods have a quicker turnaround time than virus isolation, and are performed in more laboratories. Influenza antigens can be detected by immunofluorescence, using monoclonal antibodies that distinguish between influenza A or B, or between $\mathrm{H} 3$ or $\mathrm{H} 1$ subtypes. ${ }^{7}$ Other rapid antigen detection systems include enzyme immunoassays and "point of care' tests. The point of care tests, generally based on immunochromatographic platforms using monoclonal antibodies specific to conserved regions of influenza A or $\mathrm{B}$, are simple to perform and can be used in laboratories (especially if virology resources are limited), or elsewhere, such as in doctor's surgeries, accident and emergency departments or influenza clinics. In general terms, their specificity is good (making them useful in investigating outbreaks or in surveillance) and their rapidity makes them useful for commencing antiviral therapy quickly. ${ }^{12}$ The sensitivity and specificity of the rapid antigen detection tests against influenza A/H5N1 strains are still uncertain.

Influenza-specific antibodies can be detected by various methods such as complement fixation, immunofluorescence, enzyme immunoassays, haemagglutinin inhibition and neutralisation, tests that are technically complex and difficult to perform in large numbers. Serological testing usually requires both acute and convalescent (collected four to six weeks after disease onset) samples, and has a role in detecting atypical infections and making retrospective diagnoses, and in epidemiological studies.

\section{Reliability of testing}

A challenge for Australian laboratories is ensuring that their testing is reliable for viruses not yet circulating in Australia, such as the current influenza A/H5N1 strains. Genetic variation in the viruses over time may particularly affect the reliability of $\mathrm{NAT}^{9}$, and the lack of clinical samples in Australia from influenza A/H5N1-infected individuals makes local assessment of the various methods uncertain.

\section{TABLE 2}

ROLE AND FEATURES OF LABORATORY DIAGNOSTIC METHODS USED IN AN INFLUENZA PANDEMIC

\begin{tabular}{|c|c|c|}
\hline Laboratory Method & Role & Features \\
\hline \multicolumn{3}{|l|}{$\begin{array}{l}\text { Methods specific to the diagnosis and } \\
\text { typing of the pandemic virus strain }\end{array}$} \\
\hline Nucleic acid testing & $\begin{array}{l}\text { Test of choice to diagnose } \\
\text { pandemic influenza }\end{array}$ & $\begin{array}{l}\text { Pandemic strain-specific primers will be required (eg H5). } \\
\text { Quantitation (of viral load) will not routinely be available. } \\
\text { May also be applied to non-respiratory tract samples, eg } \\
\text { serum, faeces, cerebrospinal fluid. }\end{array}$ \\
\hline Virus isolation & $\begin{array}{l}\text { Vaccine strain determination and } \\
\text { genotyping }\end{array}$ & $\begin{array}{l}\text { Will be limited to laboratories with Physical Containment } \\
\text { level } 3 \text { facilities and virus culture expertise. }\end{array}$ \\
\hline \multicolumn{3}{|l|}{$\begin{array}{l}\text { Other laboratory tests used in } \\
\text { a pandemic }\end{array}$} \\
\hline \multirow[t]{2}{*}{ Nucleic acid testing } & $\begin{array}{l}\text { To detect all influenza A H } \\
\text { subtypes, including seasonal } \\
\text { human influenza }\end{array}$ & $\begin{array}{l}\text { Uses nucleoprotein or matrix primers, or primers specific } \\
\text { for influenza } A / H 3 N 2, A / H 1 N 1 \text { and influenza B. } \\
\text { It picks all } \mathrm{H} \text { types, but doesn't separate } \mathrm{H} 5 \text { from the } \\
\text { others. }\end{array}$ \\
\hline & $\begin{array}{l}\text { To detect other respiratory } \\
\text { pathogens }\end{array}$ & $\begin{array}{l}\text { Primers can be multiplexed to detect more than one } \\
\text { virus. }\end{array}$ \\
\hline Immunofluorescence & $\begin{array}{l}\text { To detect all influenza } A \text { (or } \\
\text { human } \mathrm{H} 3 \text { and } \mathrm{H} 1 \text { ) or influenza } \mathrm{B}\end{array}$ & \\
\hline Rapid antigen or point of care tests & To detect all influenza A and/or B & Generally less sensitive than nucleic acid testing. \\
\hline H5-specific rapid antigen tests & $\begin{array}{l}\text { When assays become available } \\
\text { they may assist diagnosis } \\
\text { if a pandemic has become } \\
\text { established }\end{array}$ & Limited experience in clinical practice. \\
\hline Serology & $\begin{array}{l}\text { To detect recent influenza A or B } \\
\text { infection }\end{array}$ & H5-specific assays are not yet routinely available. \\
\hline Antiviral drug resistance testing & $\begin{array}{l}\text { To detect mutations associated } \\
\text { with neuraminidase inhibitor } \\
\text { resistance }\end{array}$ & $\begin{array}{l}\text { Genotype and phenotype assays currently limited to } \\
\text { reference or research laboratories. }\end{array}$ \\
\hline
\end{tabular}


Developing reliable tests for the pandemic strain, including quality assurance, laboratory training and use of specialised confirmatory tests (such as virus isolation), is an expensive process and not covered by current pathology funding mechanisms. Recent 'urgent research' funding through the National Health and Medical Research Council has allowed the assessment and quality assurance of various influenza A/H5N1-specific tests.

\section{DIAGNOSTIC STRATEGIES DURING A PANDEMIC}

A major challenge will be determining diagnostic strategies during the different pandemic phases. These will vary between laboratories according to their virology expertise, capacity, patient populations, and availability of various assays, and the stage of the pandemic. Table 2 lists the possible diagnostic testing approaches during a pandemic.

In the very early phases, where containment is paramount, testing will have to be rapid to identify the first arrival(s) and clusters of disease. Highly sensitive tests such as pandemic strain-specific nucleic acid testing using polymerase chain reaction or related technologies are required. However, should the pandemic be widespread in Australia (phases 6a-d, as defined in the Australian Health Management Plan for Pandemic Influenza ${ }^{1}$ ), testing strategies may change. One could argue that at this phase in the pandemic, clinical identification will suffice (as is often the case during the usual seasonal influenza outbreaks) and laboratory testing should be limited to patients requiring hospital admission or for particular outbreaks. Rapid or point of care tests, although less sensitive and less specific for the pandemic strain, may be a useful addition in these stages of the pandemic. Antiviral resistance testing, although yet not routinely available in Australia, will be important if antiviral drugs are used extensively. ${ }^{1,8}$

\section{LABORATORY WORKPLACE ISSUES DURING A PANDEMIC}

A particular challenge for laboratories will be coping with the surge of work during the early phases of the pandemic when the implications of 'positive' results are particularly high, and at a time when normal laboratory services will continue. There will be heightened community (and media) anxiety about influenza, and healthcare workers will have to deal with their own concerns about the pandemic. Issues of absenteeism, access to antiviral prophylaxis, and maintaining non-pandemic related laboratory medicine services will need consideration. Laboratory workers are generally well trained in biosafety and related infection control issues (current guidelines provide advice about laboratory precautions ${ }^{1-3}$ ), so there should be no additional work-related safety issues specific to managing specimens during a pandemic. Interactions between the public and private laboratories will need to be strengthened, given that influenza often presents to general practitioners.

\section{CONCLUSION}

There are a range of laboratory tests that detect seasonal influenza (influenza A/H3N2 and A/H1N1, influenza B), with their availability dependent on local laboratory practices and resources. Should a pandemic strain emerge, for example from the current avian influenza A/H5N1 virus, then pandemic-virus-specific tests will be needed. In this situation, specific nucleic acid testing will be the test of choice, with virus isolation also needed for evaluation of vaccine strains and genetic drift. The success of laboratory diagnosis is very much dependent on good quality specimen collection and early communication with the laboratory.

\section{REFERENCES}

1. Department of Health and Ageing. Australian Health Management Plan for Pandemic Influenza. Canberra, Department of Health and Ageing. Available at www.health. gov.au/internet/wcms/publishing.nsf/Content/ohp-pandemicahmppi.htm. Accessed 1 December 2006.

2. World Health Organization. Epidemic and pandemic alert and response. Guidelines, recommendations, descriptions. WHO. Available at www.who.int/csr/disease/avian_influenza/ guidelines. Accessed 1 December 2006.

3. Centers for Disease Control and Prevention. Avian influenza: Resources for health professionals. (US) Department of Health and Human Services. Available at www.cdc.gov/flu/ avian/professional. Accessed 1 December 2006.

4. Hien TT, Liem NT, Dung NT, et al. Avian influenza A (H5N1) in 10 patients in Vietnam. N Engl J Med 2004; 350: 1179-88.

5. The Writing Committee of the World Health Organization Consultation on Human Influenza A/H5. Avian influenza A (H5N1) infection in humans. N Engl J Med 2004; 353 : 1374-85.

6. World Health Organization. WHO Collaborating Centre for Reference and Research on Influenza. Melbourne. At www. influenzacentre.org. Accessed 1 December 2006.

7. Playford EG, Dwyer DE. Laboratory diagnosis of influenza virus infection. Pathology 2002; 34: 115-25.

8. Hayden FG. Antiviral resistance in influenza virusesimplications for management and pandemic response. $N \mathrm{Engl}$ J Med 2006; 354: 785-8.

9. The World Health Organization Global Influenza Program Surveillance Network. Evolution of H5N1 avian influenza viruses in Asia. Emerg Infect Dis 2005; 11: 1515-21.

10. Young LC, Dwyer DE, Harris M, Guse Z, Noel V, Levy MH on behalf of the Prison Influenza Outbreak Investigation Team. Summer outbreak of respiratory disease in an Australian prison due to an influenza A/Fujian/411/2002(H3N2)-like virus. Epidem Infect 2005; 133: 107-12.

11. de Jong MD, Thanh TT, Khanh THJ, Hien VM, Smith GJD, et al. Oseltamivir resistance during treatment of influenza A (H5N1) infection. N Engl J Med 2005; 353: 2667-72.

12. Sintchenko V, Gilbert GL, Coiera E, Dwyer DE. Treat or test first? Decision analysis of empirical antiviral treatment of influenza virus infection versus treatment based on rapid results. J Clin Virol 2002; 25: 15-21.

13. Dwyer DE, Smith DW, Catton MG, Barr IG. Laboratory diagnosis of human seasonal and pandemic influenza virus infection. Med J Aust 2006; 185: S48-S53. 중 